\title{
A PRODUÇÃO INTELECTUAL DE MILTON SANTOS VISTA ATRAVÉS DE SUA TRAJETÓRIA ESPACIAL: UMA INTERPRETAÇÃO
}

\author{
MÔNICA SAMPAIO MACHADO' \\ Universidade do Estado do Rio de Janeiro
}

\section{Introdução}

A minha primeira viagem a França foi a descoberta de que (...) os jornais não retratavam o mundo. (...). Quer dizer, um jornal podia ser correto, não ser desonesto, mas era a porta de entrada das agências estrangeiras. (...). E eu chego na França e abro um jornal chamado Le Monde e me pergunto: "mas o mundo é aquele que eu escrevo ou este outro?" Foi esse o meu primeiro grande choque, a primeira grande mudança na minha visão de mundo, e por conseguinte, na mina visão política. Depois, me recordo de ter visto, por exemplo, em Dakar, no Senegal, os sujeitos que ao meio-dia paravam tudo o que estivessem fazendo para se ajoelhar e virar para Meca. Tive que me perguntar: "Mas eles gostam de Deus? (...) Isso não é da igreja católica". Aí eu comecei, intelectualmente, a fazer a crítica do preconceito. Acho que as viagens me ajudaram a reduzir a carga de preconceito com que somos formados. E outra lição foi a descoberta da cultura brasileira. Negro ou não, na África eu era mesmo brasileiro. (Milton Santos, 2000:99-100)

O objetivo central deste texto é apresentar algumas reflexões sobre a produção intelectual de Milton Santos demonstrando a existência de estreita associação entre a trajetória espacial do autor e seu pensamento. Tem-se como hipótese que os lugares onde vivemos e passamos, a geografia material cotidiana e visitada, explicam, condicionam e direcionam nossa interpretação, compreensão e atuação no mundo. Os

\footnotetext{
${ }^{1}$ Professora do Departamento de Geografia Humana e do Programa de Pós-Graduação em Geografia da Universidade do Estado do Rio de Janeiro (UERJ). E-mail: monicasampaio@oi.com.br.
} 
lugares resultam do conjunto de formas e objetos espaciais com temporalidades diferentes, pelas e entre as quais os homens se movimentam. Possibilitam encontros e estabelecimentos de redes sociais de natureza diversa, políticas, econômicas, intelectuais, de trabalho e de amizade, que se alimentam reciprocamente. Independente do período temporal, quanto mais central e global for o lugar não apenas maior quantidade de informação, cultura e de agenciamentos políticos e econômicos nele se darão, condição que estará associada a sua capacidade técnica, como também maior será o alcance espacial dessas relações.

Assim, a geografia como materialidade, o ambiente global da reprodução social, isto é, o espaço geográfico como caracterizado por Milton Santos (1996), as paisagens mais a vida que as anima (o que inclui também instituições, normas políticas e culturais, a estética dos lugares, etc), desempenha papel relevante na produção das ideias e nos projetos políticos e intelectuais. ${ }^{2}$ No caso em tela, a produção intelectual de Milton Santos, inicialmente, será marcada por sua trajetória espacial que tem origens na Bahia, entre Brotas de Macaúbas, Ubaitaba, Alcobaça, Salvador e Ilhéus. Aqui se torna correspondente da Zona do Cacau para o jornal $A$ Tarde, em Salvador, e escreve o livro A Zona do Cacau, uma referência empírica para a análise das transformações advindas da economia cacaueira e também metodológica, principalmente para o estudo de rede urbana. É no espaço geográfico do estado da Bahia, entre interior e capital, que Milton Santos vive seus primeiros 24 anos, até aproximadamente o começo dos anos 50. Suas obras iniciais, aqui classificadas como pertencentes ao primeiro período do autor, Primeira sessão - Bahia, produzidas e publicadas entre 1948 e 1960, não apenas refletem temas e realidades espaciais da Bahia, a partir da ótica urbano-regional, como também o espaço geográfico regional e sua problemática política. É o Milton Santos regionalista, baiano, político e jornalista. ${ }^{3}$

2 "Paisagem e espaço não são sinônimos. A paisagem é o conjunto de formas que, num
dado momento, exprimem as heranças que representam as sucessivas relações localizadas
entre homem e natureza. O espaço são essas formas mais a vida que os anima. (...). A
paisagem se dá como um conjunto de objetos reais-concretos. Nesse sentido, a paisagem é
transtemporal, juntando objetos passados e presentes, uma construção transversal. O
espaço é sempre um presente, uma construção horizontal, uma situação única. Cada
paisagem se caracteriza por uma dada distribuição de formas-objetos, providas de um
conteúdo técnico específico. Já o espaço resulta da intrusão da sociedade nessas formas-
objetos." (SANTOS, 1996:103-104).
${ }^{3}$ A Primeira Sessão - Bahia, 1948-1960: um Milton Santos regionalista, baiano, político
e jornalista, é caracterizada pela seguinte produção intelectual do autor: 1) O povoamento 
Ainda em finais da década de 1940, Milton Santos passaria a ir com frequência ao Rio de Janeiro e São Paulo e participava de cursos livres organizados pelo então grupo de geógrafos do Conselho Nacional de Geografia, do Instituto Brasileiro de Geografia e Estatística, o IBGE, e de reuniões organizadas pela Associação dos Geógrafos Brasileiros, a AGB, que naquele momento se constituía como um apêndice do próprio Instituto. No Rio e em São Paulo, centros mais importantes de produção geográfica brasileira no período, Milton Santos toma contato não apenas com uma moderna literatura geográfica como também com geógrafos e intelectuais de expressão brasileiros e estrangeiros, principalmente franceses. Contato que vai se tornar mais efetivo em 1956, quando é realizado no Rio, então capital federal, o XVIII Congresso Internacional de Geografia. Em 1956, Milton Santos vai estudar na França, conhece Portugal, Espanha, viaja para a África e retorna ao Brasil, para Salvador.

A partir do começo dos anos 50, assim, inicia-se uma nova fase na vida do autor, novos cenários, ambientes, espaços geográficos, pessoas, enfim, novas geografias somam-se ao cotidiano e à movimentação na vida de Milton Santos. Os novos lugares lhe proporcionam condições para uma mudança de rumo de seu trabalho intelectual que irá se refletir claramente nas obras que publica cerca de quinze anos depois, a partir de 1965. É interessante observar que essa segunda fase na sua formação e nas suas redes de relações políticas e de trabalho vai sendo construída em e a partir de novas geografias, com "paisagens mais pessoas", de diferentes complexidades e sentidos. Essas novas geografias, ao mesmo tempo, vão

da Bahia: suas causas econômicas. Imprensa Oficial da Bahia, 1948, 105p; 2) Estudos sobre geografia, Tipografia Manú, Salvador/BA, 1953; 3) Os estudos regionais e o futuro da geografia. Tese (livre docência). Salvador: Imprensa Oficial da Bahia, 1953, 98p; 4) Ubaitaba: estudo de geografia urbana. Salvador: [s.n], 1954. 15p; 5) Zona do cacau: introdução ao estudo geográfico. Salvador: Imprensa Oficial da Bahia, Artes Gráficas, 1955, 110p; 6) Problemas de geografia urbana na zona cacaueira bahiana (em co-autoria com Tricart e outros) Bahia: S.N., 1956, 25p; 7) Estudos de geografia da Bahia: geografia e planejamento. Salvador: Universidade da Bahia, 1958. 243p; 8) $O$ centro da cidade do Salvador: estudo de geografia urbana. Salvador: Progresso, 1958; 9) Rede urbana do recôncavo. Salvador: Imprensa Oficial, 1959; 10) O papel metropolitano da cidade de Salvador. Bahia, Conferência no Instituto Brasileiro de Geografia (Secção da Bahia), 25 de abril de 1956, 19p; 11) A cidade como centro de região: definições $e$ métodos de avaliação da centralidade, Salvador: Imprensa Oficial da Bahia, 1959, 28p; 12) Marianne em preto e branco. Salvador: Progresso, 1960, 112p. 
lhe proporcionando ampliação e refinamento interpretativos da sociedade, evidentes em suas obras a partir de 1965, quando, já no exílio, na França, convive intensamente com intelectuais e líderes vinculados à então esquerda política.

No exílio, Milton Santos se aproximou dos marxistas através de Jean Tricart, com quem estudou a dialética sócio-espacial, que nos anos 70 reinventou e nos anos 90 seria novamente recriada por Edward Soja. Conviveu também com grandes mestres da Geografia como Josué de Castro, Pierre George, outro marxista, e Michel Rochefort. Conforme o depoimento do autor, as experiências europeia e africana do exílio muito contribuíram para sua formação intelectual e mudança política: "O meu contato sistemático com Marx data da minha ida para a Europa, para trabalhar lá. Sobretudo na África, na época do estruturalismo, em relação ao qual Sartre impediu de me entregar completamente" (SANTOS, 2000:94).

Assim, um segundo período da produção intelectual do autor pode ser identificado entre 1965 e 1987 . Aqui se evidencia um conjunto de trabalhos com unidade e interpretação diversas da primeira fase, que refletem temas como subdesenvolvimento, modernização e desigualdades sócio-espaciais, pobreza urbana, economia urbana, urbanização latino americana, renovação da ciência geográfica pelo marxismo, a construção e defesa do espaço geográfico como instância e construção social, a dialética sócio-espacial. E o Milton Santos de esquerda, internacional, metropolitano e cosmopolita, que caracteriza uma segunda fase da vida do autor, muito marcada pela sua ida para a França, a Segunda sessão - o exílio, o Mundo, entre 1965-1987: um Milton metropolitano, cosmopolita e próximo dos comunistas. A publicação do livro, em 1965, A cidade nos países subdesenvolvidos, pela Civilização Brasileira, editora na época sob o comando de Caio Prado Junior, pode ser considerada como o marco desse novo período. O último livro dessa fase é $O$ espaço do cidadão, publicado em 1987, às vésperas da Constituinte de 1988.

${ }^{4}$ Compondo a Segunda Sessão - o exílio, o Mundo, 1965-1987: um Milton Santos metropolitano, cosmopolita e próximo dos comunistas estão as seguintes bibliografias: 1) A cidade nos países subdesenvolvidos. Rio de Janeiro: Editora Civilização Brasileira, Série: Perspectivas do homem, 1965, 175p; 2) Aspects de la géographie et de l'économie urbaines des pays sous-développés.Paris: Centre de Documentation Universitaire, 1969; 3) Dix essais sur les villes des pays sous-développés. Paris, Les Procédés Dores, 1970, 121p; 4) Les villes du Tiers Monde. Paris, M-Th. Génin, 1971; 5) Modernisations et "espaces dérivés" (colaboração: Georges Coutsinas e outros), 1971; 6) Le métier de géographe en pays sous-développé : un essai méthodológique. Paris: Ophrys, 1971, 119p 
Milton Santos retorna ao Brasil em 1977, após treze anos no exterior, com 51 anos. Em função de não mais dispor de apoio político em Salvador e do convite recebido de Maria Adélia de Souza para trabalhar na área de planejamento de São Paulo, Milton Santos vai para a capital paulista e aí reside por um ano (SANTOS, 2000 e 2004). Em 1978, sem emprego, se transfere para o Rio de Janeiro, aceitando o convite de Bertha Becker para lecionar Geografia na Universidade Federal do Rio de Janeiro (MACHADO, 2009), aqui ficando até 1983, quando retorna para São Paulo e ingressa na Universidade de São Paulo (USP), como professor titular. Fixando residência na capital paulista e com a estabilidade material proporcionada pela USP, Milton Santos começaria, então, a elaborar não apenas sua interpretação sobre o Brasil, um país que muito havia mudando desde sua ida para a França, mas também sua concepção de "Geografia como filosofia da técnica".

Assim, com uma intensa agenda de estudos e pesquisas, iniciada no país em finais dos anos 70 e intensificada durante a década de 80, Milton Santos começava a preparar sua grande teoria geográfica que culminaria na interpretação do Brasil, a partir do território e de sua relação com o mundo. É daquele período também a origem da sua construção conceitual de meiotécnico-científico-informacional, tecnosfera, psicosfera e globalização, apresentada em formato final na obra que pode ser considerada a síntese teórica de seu pensamento A natureza do espaço: técnica e tempo, razão e emoção, publicada em 1996, e posteriormente aplicada ao Brasil, no ultimo livro publicado em 2001, O Brasil: território e sociedade no início do século XXI.

(Coleção Lysia e Nilo Bernardes - PGG) ; 7) Dimension temporelle et systèmes spatiaux dans les pays du Tiers Monde. Tiers Monde, v.13, n.50, avr./jun, 1972. 8) Geografia y economia urbanas en los paises subdesarrollados. Barcelona: Oikos-Tau, 1973; 9) O trabalho do geógrafo no terceiro mundo. São Paulo: Hucitec, 1978, 113p; 10) Por uma geografia nova: da crítica da geografia a uma geografia crítica. São Paulo: Hucitec, 1978, 157p; 11) Espaço e dominação. São Paulo: AGB, 1978; 12) Pobreza urbana. São Paulo: Hucitec, 1978, 119p; 13) Espaço e sociedade. Petrópolis: Vozes, 1979, 156p; 14) Espaço dividido. Rio de Janeiro: Francisco Alves, 1979; 15) Economia espacial: críticas e alternativas. São Paulo: Hucitec, 1979, 167p. 16) A urbanização desigual: a especificidade do fenômeno urbano em países subdesenvolvidos. Petrópolis:Vozes, 1980, 125p; 17) Manual de geografia urbana. São Paulo: Hucitec, 1981; 18) Pensando o espaço do homem; São Paulo: Hucitec, 1982, 58p. 19) Ensaios sobre a urbanização latinoamericana. São Paulo: Hucitec, 1982, 194p; 20) Espaço e método. São Paulo: Nobel, 1985, 88p; 21) O espaço do cidadão. São Paulo, SP: Nobel, 1987, 142p. 
Desse modo, o terceiro período da produção intelectual do autor aqui denominado de Terceira Sessão - São Paulo, a Geografia como filosofia da técnica e o Brasil na Globalização, 1988-2001: um Milton Santos cidadão do mundo, tem início em 1988, cerca de onze anos após sua volta ao Brasil, com a publicação de Metamorfoses do espaço habitado: fundamentos teóricos e metodológicos da geografia, uma de suas primeiras exposições teóricas sobre o debate da globalização e suas repercussões espaciais. ${ }^{5}$ Embora durante os anos 80 e 90 Milton Santos tenha se ausentado em várias ocasiões de São Paulo e do país, em função dos convites recebidos pelo seu reconhecimento intelectual, é interessante notar que essa terceira fase da produção do autor tem predominantemente a cidade de São Paulo como cenário. É a partir de São Paulo que Milton Santos não apenas desenvolve sua síntese teórica como também compreende o novo Brasil, agora majoritariamente urbano, e percebe a centralidade de São Paulo no comando do território nacional.

A classificação da produção intelectual de Milton Santos em três sessões, acima estabelecida, Sessão Bahia, 1948-1960: um Milton Santos regionalista, baiano, político e jornalista; Sessão, o exílio, o Mundo, 19651987: um Milton Santos metropolitano, cosmopolita e próximo dos comunistas, e Sessão São Paulo, a Geografia como filosofia da técnica e o Brasil na Globalização, 1988-2001: um Milton Santos cidadão do mundo, foi realizada a partir de um estudo detalhado de suas obras, que

\footnotetext{
5 A Terceira Sessão - São Paulo, a Geografia como filosofia da técnica e o Brasil na Globalização, 1988-2001: um Milton Santos cidadão do mundo é caracterizada pelas seguintes obras: 1) Metamorfoses do espaço habitado: fundamentos teóricos e metodológicos da geografia. São Paulo: Hucitec, 1988, 12p; 2) Metrópole corporativa fragmentada: o caso de São Paulo. São Paulo: Secretaria de Estado da Cultura: Nobel, 1990, 117p. 3) A urbanização brasileira. São Paulo: Hucitec, 1993, 157p. 4) O Novo mapa do mundo: fim de Século e Globalização; O Novo mapa do mundo: Natureza e sociedade de hoje: uma leitura geográfica; O Novo mapa do mundo: Globalização e espaço latino-americano (co-autoria Maria Adélia de Souza, entre outros) São Paulo: Hucitec / Anpur, 1993, 5) Território, globalização e fragmentação (co-autoria Maria Adélia de Souza e Maria Laura Silveira) São Paulo: Hucitec, 1994; 6) Por uma economia política da cidade: o caso de São Paulo. São Paulo: Hucitec, EDUC, 1994, 145p. 7) Técnica, Espaço, Tempo: Globalização e meio técnico-científico informacional, Hucitec, São Paulo, 1994; 8) A natureza do espaço: técnica e tempo, razão e emoção. São Paulo: Hucitec, 1996, 308p. 9) Por uma outra globalização: do pensamento único à consciência universal. Rio de Janeiro: Record, 2000, 174p; 10) O Brasil: território e sociedade no início do século XXI (co-autoria Maria Laura Silveira) Rio de Janeiro: Record, 2001, 471p.
} 
demonstrou extraordinária sintonia entre o pensamento do autor e o espaço geográfico por ele percorrido. ${ }^{6}$

Em função da importância e singularidade das obras iniciais de Milton Santos e do pouco conhecimento que se tem sobre elas, este trabalho se dedica exclusivamente a apresentar e discutir a Primeira Sessão. A produção intelectual do autor é aqui articulada a sua biografia, vivida naquele período predominantemente na Bahia. Buscando conhecer o sentido do seu pensamento, particular atenção é dada ao cenário político partidário baiano, bastante marcado naquele momento pela atuação da corrente "udenista".

\section{A Primeira Sessão - Bahia, 1948-1960: um Milton Santos regionalista, baiano}

Milton de Almeida Santos, filho de Francisco Irineu dos Santos e Adalgisa Umbelina de Almeida Santos, nasceu em Brotas de Macaúbas, $590 \mathrm{~km}$ da capital baiana, Chapada Diamantina, interior da Bahia, em 3 de maio de $1926 .^{7}$ Egressos de Salvador, seus pais haviam se mudado para Brotas de Macaúba onde morava o irmão mais velho de sua mãe, então advogado, para ensinar como professores primários. ${ }^{8}$

No início do ano de 1927 a família Santos sai de Brotas e vai residir em uma cidade próxima a Ilhéus, na então denominada cidade de Itapira, a $369 \mathrm{~km}$ ao sul de Salvador, Zona do Cacau, que posteriormente passaria ao nome de Ubaitaba, por decisão do IBGE, uma vez que havia uma cidade em São Paulo com a mesma denominação. ${ }^{9}$ Aos três anos de idade,

${ }^{6}$ Dentre as classificações desenvolvidas sobre a produção intelectual do autor, cabe destaque a elaborada por Denise Elias, 2002.

${ }^{7}$ Brotas de Macaúbas teve suas terras exploradas em final do século XVIII. Região dos primeiros diamantes da então província da Bahia, seus habitantes eram garimpeiros e pessoas que trabalhavam na extração e comercialização de diamantes. Na segunda década do século XX, Brotas e localidades vizinhas foram cenário de disputas violentas entre coronéis e seus jagunços. A economia da cidade outrora próspera pela extração de diamante e ouro, no inicio do século XX era movimentada pela criação de gado, em grandes latifúndios.

${ }^{8}$ Maria Auxiliadora da Silva (2002) e Milton Santos (2000).

${ }^{9}$ Situada ao norte de Ilhéus, Ubaitaba formou-se à margem do rio das Contas, numa planície entre as colinas e o rio, em função do desenvolvimento da Capitania de São José dos Ilhéus, ficando sua identidade muito associada ao litoral sul da Bahia. Sua origem 
provavelmente em 1929, os pais de Milton Santos mudam-se para Alcobaça, cidade da zona do Extremo Sul da Bahia, porção que é também enquadrada por Milton Santos (1948:11-15) como participante da zona cacaueira ou, como prefere denominar, região cacaueira, onde ficará até os dez anos. ${ }^{10}$ Aqui, faz o primário com os pais que lhe ensinam também o francês. Seus dois irmãos nascem em Alcobaça.

Aos dez anos, possivelmente em 1936, é enviado pelos pais para Salvador, para estudar como interno no Instituto Baiano de Ensino, colégio tradicional na época, dirigido pelo Professor Hugo Baltazar da Silveira, destacado professor em Salvador. ${ }^{11} \mathrm{O}$ Instituto era um colégio privado e

relaciona-se à criação do Arraial de Faisqueira (1783), então área destinada à extração de madeira, à cultura da cana de açúcar, dos cereais e do cacau, hoje um dos três distritos de Ubaitaba. Com o tempo surgiram estradas para conduzir os trabalhadores às roças e escoar os produtos das lavouras. No inicio do século XX, Ubaitaba fazia parte da área central da Zona do Cacau.

${ }^{10}$ Alcobaça tem origem em uma vila criada em finais do século XVIII, situada às margens do rio Itanhém, ao sul da Capitania de Porto Seguro (extremo sul da Bahia, hoje fazendo parte da região conhecida como Costa das Baleias). No decorrer do século XIX, Alcobaça floresceu com suas fazendas imponentes de cacau, que tiveram seu auge no final do século XIX e início do XX, sob o comando dos coronéis. A cultura do cacau no Brasil é concentradora de posse de terra, principalmente na Bahia. A vocação turística de Alcobaça fica mais forte no final do século XX.

${ }^{11}$ A cidade de Salvador, capital do Estado da Bahia, a mais antiga das cidades brasileiras, foi construída para ser a capital do país e durante três séculos foi a sua mais importante aglomeração urbana. Apesar do eixo da economia nacional ter se deslocado para o sul e a capital baiana ter vivido entre os anos 1920 e 1940 um período de quase estagnação, em 1940 sua população era de aproximadamente 290 mil habitantes, então a quarta cidade mais populosa do Brasil, ficando atrás do Rio Janeiro, São Paulo e Recife. A metrópole baiana ofereceu a Milton Santos um ambiente de reprodução social fundamental para sua formação política e intelectual. Como importante centro político e cultural regional, bem diferente da capital paulista e carioca, uma vez que, conforme o próprio depoimento de Milton Santos (2000:77), coexistiam em Salvador uma cultura que misturava o peso do mundo agrícola, do comércio e do cartório, onde os jornais e os bancos estavam nas mãos de poucas famílias, e de certa forma a universidade também, a cultura clássica tinha um certo peso e representava a produção do futuro e o espaço geográfico da cidade ofereceu ao autor as condições para a construção desse futuro. Salvador torna-se mais tarde tema de sua tese de doutorado, defendida, em 1958, na Faculdade de Letras da Universidade de Estrasburgo, sob orientação de Jean Tricart e Etienne Juillard, publicada no Brasil em 1959, sob o título $O$ centro da cidade de Salvador: estudo de Geografia Urbana. Com este estudo Milton Santos passaria a ser reconhecido pela comunidade geográfica francesa. 
leigo para onde iam judeus, espanhóis e uma certa "classe média" e onde o pai de Milton Santos havia lecionado antes de ir para o interior da Bahia. Morando em Salvador, Milton Santos de dois em dois anos visitava os pais em Alcobaça e em anos alternados os pais iam para a capital, situação que vai perdurar até 1940, quando seus pais retornam para morar em Salvador. ${ }^{12}$

Como era comum na formação da elite culta brasileira do período dispor de excelentes professores ensinando um amplo leque de conhecimento como filosofia, ciências e arte, a formação de Milton Santos não foge à regra. Em Salvador, no ginásio e no curso preparatório para o ensino superior, estuda várias áreas de conhecimento como Literatura, Física, Química, Matemática, História natural, Filosofia, Geografia etc. O livro Geografia Humana, de Josué de Castro, um compêndio didático publicado em 1939, destinado ao ensino médio, era adotado pelo Instituto Baiano de Ensino e não só fez parte de sua formação como lhe influenciou. ${ }^{13}$ Com quinze anos, isto é, no quinto ano de ginásio, em 1941, Milton Santos se formou como bacharel em Ciências e Letras. O diploma de bacharel representava o reconhecimento do aluno que estudasse no ginásio e também um passo na produção do homem de elite. Nos dois anos seguintes cursou o preparatório pré-jurídico no Colégio da Bahia para ingressar no ensino superior, na Faculdade de Direito (SILVA, 2002 e SANTOS, 2000)

Segundo depoimento do próprio Milton Santos o mundo do ginásio e do curso suplementar era um mundo à parte. Um mundo que preparava os jovens intelectualmente para desempenhar cargos de comando notadamente na esfera política-institucional, principalmente na Bahia, uma vez que a antiga elite via no serviço público fonte de poder e de segurança,

\footnotetext{
${ }^{12}$ Maria Auxiliadora da Silva (2002) e Milton Santos (2000).

${ }^{13}$ Até 1939, Josué de Castro havia publicado vários livros que já demonstravam grande erudição. Articulavam seus estudos e pesquisas em Literatura, Medicina, Fisiologia, Endocrinologia, Nutrição, Antropologia, Psicanálise e Geografia, como: Condições de vida das classes operárias do Recife e $O$ problema fisiológico da alimentação no Brasil, em 1932; A Questão do Salário Mínimo e Alimentação e Raça, em 1935; Alimentação brasileira à luz da Geografia Humana, em 1937; Documentário do Nordeste, Geografia Humana: Estudo da Paisagem Cultural do Mundo e Ensaios de Geografia Humana, em 1939. Além desta literatura, Josué de Castro nos anos 20 já havia publicado artigos e crônicas sobre vários temas como ciência, literatura, pintura, cinema em periódicos como Revista de Pernambuco, Diário da Manhã e Revista de Antropofagia. (http://www.projetomemoria.art.br/JosuedeCastro, Manuel Correia de Andrade, 1997)
} 
uma forma de manutenção dos prestígios familiares dos séculos passados sustentados na propriedade de terra, açúcar e gado. ${ }^{14}$

\begin{abstract}
(...) éramos ensinados a não gostar de futebol, sobretudo gente como eu, que tinha origem visivelmente inferior, e que as famílias preparavam para as funções de mando. A educação que me foi dada não foi a de obedecer, foi para me preparar para fazer parte dos que iam mandar. Como é que iria gostar de futebol? Não podia. (...). Todas as atividades ditas populares eram desaconselhadas (...) na produção do homem de elite, do bacharel. E o que é o bacharel? É um sujeito que pode ser advogado, promotor, juiz, jornalista, político, diretor de hospital. (...). E que aprende a falar, o que era uma característica do mando e da política, saber fazer frases, saber amarrar uma idéia com a outra. E como não tinha televisão, a minha geração se reunia para conversar, para ouvir poesia, para ouvir o que o outro escreveu, elaborar jornais manuscritos (...). Havia um apreço à história da cultura, porque se considerava que a cultura abria as portas, e o pior é que abria mesmo. Em São Paulo havia o industrialismo e o peso do dinheiro, uma outra escala de valores. Na Bahia não havia o tipo de riqueza que havia aqui. Enfim, pode ser uma interpretação baiana da história brasileira, ou uma vontade de contrastar a origem baiana à origem, digamos paulista. (SANTOS, 2000)
\end{abstract}

Ainda no ginásio Milton Santos passou a lecionar Geografia Humana. Então, quando ingressou na Faculdade de Direito, em 1944, em Salvador, já trabalhava como professor (de Geografia) e seu salário auxiliava parte de suas despesas. Pertencendo à elite culta baiana, Milton Santos em Salvador participou da vida política regional. No início dos anos 40 fundou com amigos a Associação de Estudantes Secundaristas Brasileiros, uma associação nordestina que incluía Pernambuco, Sergipe e Paraíba, dissidente da União Nacional dos Estudantes. Milton Santos

\footnotetext{
${ }^{14}$ Embora o compadrio não tenha sido exclusividade baiana, na Bahia era muito forte $\mathrm{e}$ aparente. Conforme Israel O. Pinheiro (1999:59), na Bahia os concursos públicos selecionavam integrantes das famílias conhecidas e, feita a nomeação, a elite se perpetuava no poder. O depoimento de Milton Santos é, nesse sentido, exemplar; perguntado sobre sua perspectiva profissional, respondeu: "Meu desejo era ser professor de Teoria Geral do Estado (...) mas havia um professor dessa área, um homem jovem, um grande nome, Nestor Duarte. E ele tinha um filho. Logo descobri que eu não ia jamais chegar lá, porque o lugar era para o filho". (Milton Santos, 2004:51)
} 
assumiu a presidência da Associação, embora tenha tido problemas com o Partido Comunista que não o apoiou inicialmente para o cargo por considerar difícil o relacionamento de um negro com autoridades. Este evento interferiu na sua relação com os comunistas, problema que só será resolvido posteriormente, quando vai para França realizar seu doutorado com o geógrafo comunista Jean Tricart, em 1956 (SANTOS, 2000).

É interessante observar que a entrada de Milton Santos na política não vai ocorrer pela esquerda, mas pela oposição ao Governo Vargas, com grande expressão no regionalismo baiano. A inserção de Milton Santos, então, no mundo político e intelectual desse período, só pode ser entendida ao se considerar as condições oferecidas pelo espaço geográfico da Bahia, evidentes na produção intelectual da primeira Sessão, Sessão Bahia, 19481960: um Milton Santos regionalista, baiano.

Chega, então, o empurrão da Faculdade de Direito. E a confusão, naquele período, que se repetiria de novo no Brasil dos anos 80, entre a oposição e a esquerda. Nós éramos oposição à ditadura. Muitas pessoas ainda não se curaram dessa confusão entre oposição e esquerda. Porque estavam todos juntos na luta para derrubar a ditadura. A faculdade de Direito é o lugar da elite e as minhas relações pessoais, meus amigos, as pessoas com quem eu me dava bem, eram de famílias importantes. De outro lado, tinha esse choque pessoal com a turma do Partidão, um ressentimento que eu guardava (...). Chego à faculdade em 1944, em plena abertura para a democracia. Estávamos todos juntos pedindo a entrada do Brasil na Segunda Guerra (...).Esse pano de fundo é importante para entender porque a minha ida para a esquerda foi lenta e intelectual, não foi resultado de uma militância, foi resultado de um aprendizado, é parte de uma redescoberta do mundo que eu fiz na Europa. (SANTOS, 2000:80-81)

${ }^{15}$ Em 1956 Jean Tricart estava no Brasil para participar do XVIII Congresso Internacional de Geografia da União Geográfica Internacional (UGI), realizado no Rio de Janeiro. Esse evento foi de extrema importância para a Geografia brasileira, consolidando ainda mais o campo de atuação da Geografia científica, à época uma disciplina muito prestigiosa. Participaram de sua realização a Universidade do Brasil, o IBGE e a Universidade de São Paulo. O Congresso abriu as portas dos geógrafos brasileiros para o mundo e grandes nomes da Geografia aqui estiveram. Milton Santos vem ao Rio para participar desse Congresso e estabelece relações estreitas com geógrafos franceses, sobretudo Tricart. (MACHADO, 2009). O Rio foi, então, sua porta para o mundo. 
Em função de certa estagnação econômica do Recôncavo e da Bahia, na década de 1940 fortalecia-se na elite política e intelectual baiana um regionalismo não apenas fruto de uma herança cultural ou "geográfica", mas uma forma de alcançar o progresso dentro da nação, cada vez mais identificado com o desenvolvimento industrial, já naquele momento com força em São Paulo. Essa era a ideia comum entre as correntes políticas progressistas da direita e da esquerda e do partido comunista: a indústria resolve (SANTOS, 2000:78-79). Esse regionalismo se expressava na década de 1940 em clara oposição ao Rio de Janeiro, na época capital federal, e, sobretudo, ao Governo Vargas. Assim, a atuação política de Milton Santos na década de 40 e, posteriormente, na de 50, esteve diretamente associada a esse movimento regional que tinha dentre os representantes os então udenistas Juracy Magalhães ${ }^{16}$, João Mangabeira e Otávio Mangabeira, ${ }^{17}$ os dois últimos da Esquerda Democrática, grupo que

${ }^{16}$ Juracy Magalhães, cearense, segue a carreira militar e, juntamente com Juarez Távora, apóia a Revolução de 30. Em 1931 é nomeado interventor federal da Bahia, construindo um novo pacto político no estado ao criar o PSD da Bahia, assegurando o apoio a Vargas contra o movimento Constitucionalista de 1932, deflagrado em São Paulo e com apoio da Bahia. Em 1935-1937, é eleito governador do estado. Em 1937, opõe-se a Getúlio e reassume suas atividades no Exército, regressando na política em 1945 através da UDN, fazendo parte da comissão executiva nacional, chegando a ser seu presidente entre 1957 e 1959. Entre 1959-1963 assume novamente o governo da Bahia pela legenda da UDN. Disputa com Jânio Quadros a indicação para a candidatura da UDN à presidência da República, em 1960, mas é derrotado na Convenção. Passou o governo para Antonio Lomanto Junior, em 1963. Apoia o Golpe de Estado Militar de 1964. (Dicionário Histórico-Biográfico Brasileiro, CPDOC, Fundação Getulio Vargas)

${ }^{17}$ Os irmãos baianos de Salvador, João Mangabeira, advogado e político e Otávio Mangabeira, engenheiro, político e intelectual, integravam uma importante corrente política baiana denominada de "concentração autonomista". Em luta permanente contra o getulismo, essa corrente havia sido formada em 1932 e tinha também como líderes Ernesto Simões Filho, fundador do jornal A Tarde e Nestor Duarte, prestigioso mestre do Direito, político e escritor, autor de importantes romances da literatura baiana e fundador do Jornal da Bahia. "O autonomismo surgiu em 1932 com o nome de Liga de Ação Social e Política. Denominou-se de 'liga' porque os partidos políticos haviam sido banidos pelo Estado Novo. Os autonomistas (...) se contrapunham aos "invasores" ou "holandeses" (...), ou seja, eram contrários a Juracy Magalhães e seu grupo político, vindos de fora e levados ao governo do Estado pela interventoria" (GOMES, 2001). João Mangabeira manifesta-se a favor da Revolução Constitucionalista de São Paulo de 1932 e em 1936 é preso por acusação de envolvimento com os comunistas que influenciavam a Aliança Nacional Libertadora (ANL) contra a Ação Integralista Brasileira (AIB). Ingressa na Esquerda Democrática, em 1945, inicialmente vinculada UDN e posteriormente, em 
o próprio Milton Santos caracterizava como de "vocação para a esquerda e amarras na direita" (SANTOS, 2000:79) e que atuava no interior da União Democrática Nacional (UDN), partido de oposição a Getúlio, criado em 1945 e extinto em 1964 pelo AI-2. Embora compusessem o mesmo partido, grandes eram as rivalidades entre Juracy Magalhães e o grupo de Otávio Mangabeira.

Com o fim do primeiro Governo Vargas, em 1945, após anos de ilegalidade, os partidos políticos retornavam ao cenário nacional. É nesse contexto que surgia a UDN. Não se pode esquecer que nos anos 40 o Brasil refletia, a sua maneira, o conflito internacional dividido em dois grandes grupos, os integralistas e os comunistas. Desde que os Estados Unidos entraram diretamente na Guerra, em 1941, e, posteriormente, toda a América, com exceção do Canadá, que já havia ingressado em 1939, o Brasil mudou de lado e aliou-se aos Estados Unidos e Grã-Bretanha, contra a Alemanha, passando a desenvolver um visível impulso democrático. À medida que se espalhava a democracia na Europa, então, aumentava no país a defesa pela democracia e enfraquecia-se o poder repressivo da ditadura de Vargas no Estado Novo. Assim, em 1945, com o fim da Guerra, foram aprovadas medidas pelo próprio Estado que admitiam a formação e a legalização de partidos políticos e a obrigatoriedade de seu âmbito nacional (FRANCO, 1980). É nesse momento que a UDN é formada.

A UDN, na realidade, expressava uma "associação de partidos estaduais e correntes de opinião" contra a ditadura estadonovista e as representações de Getúlio, tendo por isso eleito vários governadores, especialmente, no Nordeste. É importante lembrar que a vida partidária brasileira entre 1945 e 1965, apesar de ao final deste período contar com treze partidos, esteve polarizada, de um lado, entre os partidos getulistas, o PSD e o PTB, e, de outro, o principal partido antigetulista, a UDN. O Partido Comunista, apesar de ter sido legalizado em 1945, em 1947 tem

1947, no Partido Socialista Brasileiro (PSB), tornando-se seu presidente. Otávio Mangabeira foi exilado em 1930 e em 1938. Em 1945 ingressa na UDN e assume sua a direção nacional até 1947. Defende posteriormente a aproximação da UDN a Eurico Dutra, do PSD, objetivando uma possível coligação dos dois partidos para a eleição presidencial de 1950. Mas a oposição dentro da UDN consegue passar o nome do brigadeiro Eduardo Gomes, que perde as eleições para Getúlio. Em 1954 participa da campanha contra Vargas e em 1959 elege-se senador pelo estado da Bahia. (CHACON, 1998:152); (Dicionário Histórico-Biográfico Brasileiro, CPDOC - Fundação Getulio Vargas, http://www.cpdoc.fgv.br/comum/asp/idx_monta_login.asp). 
seu registro cancelado e, no ano seguinte, seus parlamentares são cassados, no governo Eurico Gaspar Dutra. O PSD aglutinava as correntes mais conservadoras a favor de Getúlio, formada por proprietários rurais e por altos funcionários estatais. O PTB, inspirado no Partido Trabalhista do Reino Unido, aglutinava as lideranças sindicais e os operários fabris em geral (CHACON, 1998).

A UDN era, desse modo, o partido rival, liberal e antipopulista, composto pela alta burguesia e a classe média urbana, defensora do capital estrangeiro e da iniciativa privada, tendo sido a principal promotora das impugnações das vitórias eleitorais da coligação PSD-PTB nos cinco primeiros anos da década de 50, e a maior instigadora das tentativas de golpes não apenas contra Getúlio, mas também contra Juscelino Kubitschek, Jânio Quadros e João Goulart. Essa forma de atuar do partido expressava, de certa maneira, suas desavenças internas. Assim, embora em todos estados a UDN rivalizasse com o PSD, internamente as disputas entre os grupos eram grandes, às vezes mais aguda do que a posição ao partido adversário. Isso explica as coligações eleitorais aparentemente estranhas, geralmente com os adversários no plano nacional, PSD e PTB, ou com o partido do paulista Ademar de Barros.

As divergências internas da UDN podem ser agrupadas em três tendências: 1) os oligarcas destituídos politicamente em 1930 (aqui estavam os autonomistas baianos, como Otávio Mangabeira); 2) os tenentistas militares e civis (aqui estava Juracy Magalhães); 3) os liberais convencionais. Assim, até sua extinção em 1964, a UDN se estabelecia como uma autêntica Arca de Noé, mas com o rumo sempre apontado para centro-direita (CHACON, 1998:15).

Essa "Arca de Noé", ao se firmar inicialmente pela expressiva oposição liberal a Getúlio, foi forte principalmente em Minas Gerais,

18 Em 1945 Ademar de Barros se filiava a UDN, porém em 1946 cria o Partido Republicano Progressista (PRP), que pouco depois se fundiria ao Partido Popular Sindicalista e ao Partido Agrário Nacional, formando o Partido Social Progressista (PSP), que se tornou o maior partido político de São Paulo do período de 1946 a 1964, com diretórios em todos os municípios do estado de São Paulo. Foi governador de São Paulo entre 1947 e 1951, prefeito de São Paulo entre 1957 e 1961. Após a renúncia de Jânio, um grande adversário político, em 1962, durante a fase parlamentarista, o partido de Ademar (PSP) aliou-se à UDN no combate ao retorno do presidencialismo desejado pelos partidários de Goulart. Assumiu o governo de São Paulo em 1963, apoiando o golpe militar e a indicação do general Castelo Branco. Entretanto, é cassado em 1966. (Dicionário Histórico-Biográfico Brasileiro, CPDOC - Fundação Getulio Vargas) 
Guanabara, Bahia, Paraíba e Rio Grande do Norte. Secundária, porém com força relativa constante, no estado do Rio, em Pernambuco, em Alagoas, Mato Grosso, Piauí, Santa Catarina, Sergipe e Ceará. No estado do Rio, em virtude da hegemonia do PSD de Ernâni Amaral Peixoto, a UDN eventualmente se aliava ao PTB. Era muito heterogênea, reunindo bacharéis no velho estilo liberal ao lado de conservadores mais "linha dura" e líderes populistas como Tenório Cavalcanti. Já a UDN carioca era ativíssima, com apoio na imprensa, em setores das forças armadas (os brigadeiristas tradicionais e os lacerdistas) e na igreja católica. ${ }^{19} \mathrm{Na}$ Bahia a UDN havia resultado da fusão de basicamente duas correntes adversárias até 1937, que se aproximaram na luta contra o Estado Novo: os "juracisistas" (vinculados a Juracy Magalhães, antigo "tenente" favorável à revolução de 1930), e os "autonomistas" (vinculados ao político da República Velha, Otávio Mangabeira). Em São Paulo a UDN era derrotada não apenas pelo Partido Social Democrata (PSD, também fraco no estado), mas pelos populismos de Ademar de Barros e Jânio Quadros (FRANCO, 1980). ${ }^{20}$

Do ponto de vista institucional o partido era um só, apresentando um sentimento de identidade sustentado na devoção aos heróis comuns e à aversão aos inimigos comuns (a polarização antigetulista), na crença nos mesmos princípios (anti-estatismo, anti-comunismo), e no estilo de entender a política pelo elitismo do "sentido de excelência" por um lado, e pelo moralismo, por outro. Assim, apesar dos conflitos e divisões internas, do ponto de vista global a história da UDN pode ser resumida em três fases distintas. A primeira, de oposição sistemática a Getúlio, principalmente quanto à política social e à intervenção do Estado na economia, predominante até fim do segundo governo Vargas, até 1954. A segunda, de denúncias de corrupção administrativa, principalmente contra a aliança governista PSD-PTB (Juscelino e Jango), o que explica, em parte, a aproximação com o moralismo "janista", embora essa aproximação não tenha se dado com apoio da maioria udenista, dividida entre Jânio e Juracy. A última fase é a do anticomunismo radical, de reaproximação com o

\footnotetext{
${ }^{19}$ Dicionário Histórico-Biográfico Brasileiro, CPDOC - Fundação Getulio Vargas.

20 "Contradições e cisões acompanharam a trajetória udenista. Coexistiram na UDN teses liberais e autoritárias, progressistas e conservadoras. O partido que vota a favor do monopólio estatal do petróleo (1953) e contra a cassação dos mandatos dos parlamentares comunistas (1947) é o mesmo que se opõe à intervenção do Estado na economia, denuncia a "infiltração comunista" na vida pública e contesta os resultados quando perde as eleições". (Dicionário Histórico-Biográfico Brasileiro, CPDOC, Fundação Getulio Vargas)
} 
paulista Ademar de Barros, culminando no apoio ao golpe militar e na participação ativa na deposição de João Goulart, em $1964 .{ }^{2}$

Especificamente no espaço geográfico em tela, a Bahia, embora a UDN fosse muito forte e exercesse pressão em bloco na política nacional, o conflito interno entre os "juracistas" e "autonomistas" fazia com que ela se apresentasse literalmente dividida. $\mathrm{Na}$ realidade os "juracistas" representavam os interesses da oligarquia rural baiana, do interior, fortalecida principalmente com a interventoria de Juracy Magalhães, em 1930, que se estabeleceu buscando apoio no interior, uma vez que a oligarquia local era totalmente avessa à interferência do governo Federal. Já os "autonomistas", representavam os interesses da tradicional oligarquia, a oligarquia urbana, os coronéis urbanos, principalmente de Salvador e Ilhéus, contrários às mudanças impostas pelo centralismo de Vargas (PINHEIRO, 1999:66-68). É dentro desse contexto que se movimentou a elite política e intelectual baiana até meados do século XX.

No final dos anos 50 uma grande aliança foi estabelecida na Bahia entre a UDN juracista e seus históricos adversários, do velho autonomismo, herdeiros de Otávio Mangabeira e Ernesto Simões Filho, em torno da implementação de um projeto industrializante no estado. Assim, em 1958 a UDN se torna hegemônica e Juracy Magalhães é eleito governador. Em 1960, em função da disputa pela indicação do candidato da UDN para a presidência da República entre Juracy Magalhães e Jânio Quadros, acirram-se as rivalidades dentro do partido. No plano nacional, a UDN ficava dividida entre os que apoiavam Juracy, candidato também de Juscelino Kubitschek (PDS), e os que defendiam Jânio, candidato do Partido Democrata Cristão (PDC) e do Partido Socialista Brasileiro (PSB), apoiado por um dos principais líderes da UDN, Carlos Lacerda, à época governador da Guanabara, posteriormente um dos instigadores da renúncia do próprio Jânio. Essa divisão vai também movimentar a UDN baiana,

${ }^{21}$ Após a extinção dos partidos, em 1964, a maior parte dos políticos da UDN migraram para a Aliança Renovadora Nacional (ARENA). Carlos Lacerda e Kubitschek e criam um movimento de redemocratização do país, a Frente Ampla, com apoio de João Goulart que, entretanto, foi cassado pela ditadura em 1966. (Dicionário Histórico-Biográfico Brasileiro, CPDOC, Fundação Getulio Vargas; KOIFMAN (org.), 2002). "Dois partidos surgiram com a dissolução dos treze partidos anteriores: a Aliança Renovadora Nacional (ARENA) e o Movimento Democrático Brasileiro (MDB). A primeira reunindo basicamente udenista e pessedistas, com adesistas dos mais variados tipos, e o segundo unindo os discordantes do golpe-revolução de 1964, sobretudo petebistas, com alguns pessedistas e raros udenistas e demais." (CHACON, 1998:191) 
promovendo novas articulações. Em 1963, Antônio Lomanto Junior, do grupo dos autonomistas aliado a Otávio Mangabeira, sucede Juracy no governo da Bahia, que na época contava também com sustentação do PTB "janguista" ${ }^{22}$ Logo após as eleições cresceram as tensões entre posições nacionais que haviam apoiado Lomanto Junior, alinhadas a Jango, e as alianças locais da UDN, anticomunistas, juracistas e autonomistas. Até o golpe de 1964 aumentam as influências de Juracy Magalhães no governo da Bahia, que já naquele momento acompanhava a posição nacional udenista a favor da intervenção dos militares para afastar João Goulart. Assim, com o apoio de Antonio Carlos Magalhães, na época presidindo a UDN baiana, o governo da Bahia, sob o comando de Lomanto Junior, apoia o golpe militar e a deposição de João Goulart.

Com o quadro descrito acima é possível agora retornar à biografia de Milton Santos e melhor contextualizar a atuação e movimentação do autor no mundo político e intelectual do período, assim como suas opções profissionais até 1964. É possível igualmente avaliar com mais acuidade não apenas as obras que produziu no período, mas sua extensa e diversificada produção intelectual, uma vez que os lugares não apenas oferecem potencialidades de reprodução social, como também são internalizados, compondo matrizes interpretativas. Assim, apesar de Milton Santos ter se afastado do regionalismo baiano, sua rede de relações, seu pensamento como um todo e sua forma de interpretação de mundo podem ser mais bem entendidos se não forem desconsiderados os condicionantes geográficos da Bahia. É a partir da Bahia que se lança no Brasil e no mundo, passando a percorrer outros contextos geográficos que vão sendo associados ao contexto baiano, renovando-os e ampliando-os. Isso não significa, contudo, a defesa de um determinismo histórico-espacial como orientação de análise, mas sim a tentativa de demonstrar que os lugares são dimensões fundamentais para o a apreensão do sentido do pensamento, de sua raiz e essência.

Milton Santos, conforme visto, tem sua vida profissional e intelectual iniciada dentro desse contexto baiano. Após concluir o curso de Direito em Salvador, em 1948, passou a morar também em Ilhéus e vir com frequência ao Rio para participar do curso de férias do IBGE e das reuniões da AGB,

\footnotetext{
22 Antônio Lomanto Júnior (baiano) elege-se por duas vezes prefeito de Jequié e deputado estadual, antes de assumir o governo da Bahia entre 1963-1967. Apoia o regime militar em 1964, tornando-se uma das lideranças da ARENA sob o comando de Antonio Carlos Magalhães.(CHACON, 1998:191)
} 
que aglutinavam naquele momento os geógrafos do eixo Rio-São Paulo para realização de pesquisas de campo, de discussões e apresentações de trabalhos, de reuniões com políticos para avaliação de estratégias de planejamento etc. Durante o início dos anos 50, assim, morando em Salvador e Ilhéus e visitando o Rio de Janeiro, Milton Santos dividia seu tempo, principalmente, com a política, as aulas e pesquisas em Geografia Humana e com as atividades jornalísticas, um jornalista profissional. Em Ilhéus, inicialmente, leciona no Colégio Municipal de Ilhéus e advoga na área penal e de direito comercial marítimo. Posteriormente, torna-se correspondente da Zona do Cacau para o importante jornal de Salvador $A$ Tarde, de propriedade de Ernesto Simões Filho, do então grupo autonomista baiano, possibilitando a redação do seu livro A Zona do Cacau, publicado em 1955 (SANTOS, 2000 e 2004). Em Ilhéus conhece Jandira Rocha, com quem tem seu primeiro filho, Milton Santos Filho.

Escrevendo com regularidade para este jornal, Milton Santos deixa Ilhéus e vai morar apenas em Salvador, entre 1955 e 1956. Em finais dos anos 50 torna-se redator do $A$ Tarde e, posteriormente, um dos responsáveis pelo seu editorial, expressando, desse modo, a opinião institucional do jornal. Também em finais dos anos 50 assumia a direção da Imprensa Oficial do Estado da Bahia, no segundo mandato do udenista Juracy Magalhães (SANTOS, 2000 e 2004). E interessante observar que Milton Santos não apenas trabalhou, mas, sobretudo, assumiu cargos de comando tanto no setor privado, no jornal A Tarde, de expressão da oligarquia urbana baiana, dos udenistas autonomistas, quanto na administração pública, na Imprensa Oficial da Bahia, onde são divulgados os atos, normas e programas de governo, no mandato de Juracy Magalhães, representante da oligarquia rural baiana, naquele momento aliado aos adversários autonomistas.

É em finais da década de 40 e início da década de 50, então, que Milton Santos passaria a sair da Bahia e vir com frequência para o Rio e, posteriormente, São Paulo, ampliando e diversificando sua rede de relações. Nas capitais carioca e paulista estabeleceu contatos mais estreitos com os geógrafos, políticos e intelectuais franceses e de todo o território brasileiro. Em 1956, vem ao Rio para participar do XVIII Congresso Internacional de Geografia da União Geográfica Internacional (UGI), estreitando contato com o geógrafo francês Tricart, que o convidou para fazer o doutorado na França, convite que fora prontamente aceito. Em 1958 defendia, assim, sua tese na Universidade de Estrasburgo, sob orientação de Tricart e Étienne Juillard. Em 1959, a tese foi publicada no Brasil sob o título O centro da cidade de Salvador: estudo de Geografia Urbana. Antes 
de retornar ao país, Milton Santos viajou para Portugal, Espanha e África. Com apoio do governo francês, conseguido por Tricart em 1958, Milton Santos teve a oportunidade de conhecer diversos países africanos, que na época deixavam de ser colônias francesa. A África seria novamente por ele visitada, primeiramente no governo Jango, quando foi enviado em missão política para conversar com diversos presidentes e, posteriormente, no período do exílio (SANTOS, 2000 e 2004; SILVA, 2002). As experiências europeia e africana foram fundamentais para o autor e podem ser claramente percebidas no último livro dessa primeira fase, publicado em 1960, Marianne em preto e branco.

Após seu retorno do doutorado na França conhece o então reitor da Universidade Federal da Bahia, Edgard Santos, que o encarrega de organizar um grupo de pesquisa, em cujo nome, entretanto, não deveria constar a palavra Geografia, uma vez que a direção não seria dos professores da Universidade. Assim, com o apoio do reitor e de Tricart, que estava naquela oportunidade em Salvador representando a Cooperação Técnica Francesa, criou o Laboratório de Geomorfologia e Estudos Regionais da Universidade da Bahia, em 1959. Nesse mesmo ano, Milton Santos organizou o IV Colóquio Internacional Luso-Brasileiro, com o patrocínio da Universidade da Bahia e da UNESCO, reunindo professores de várias partes do campo da Geografia e das ciências sociais (SILVA, 2002). Assim, ampliou sua rede de relações e passou a realizar pesquisas, publicar livros, convidar colegas estrangeiros, principalmente franceses, e brasileiros, com destaque para os paulistas, como Aroldo de Azevedo, Araújo Filho, Aziz Ab'Saber etc. Entre 1956 e 1960, esteve vinculado à Universidade Católica da Bahia, lecionando Geografia Humana e, nos anos de 1960 e 1961, à Universidade Federal da Bahia, também como professor de Geografia Humana (SANTOS, 2000 e 2004; Silva, 2002).

Com o doutoramento, a criação do Laboratório e, sobretudo, suas "experiências geográficas" no Rio, São Paulo, Europa e África, Milton Santos passou a ter presença marcante na vida acadêmica e nas atividades jornalísticas e políticas de Salvador. No início dos anos 60, assim, já se destacava na sociedade baiana, com articulações estabelecidas no importante jornal da cidade, A Tarde, no governo do estado, na Imprensa Oficial e agora na Universidade Federal como catedrático. Através dessas atividades começava também a ser reconhecido nacionalmente. Durante os primeiros anos da década de 60, a partir da Bahia, Milton Santos preparou, então, sua inserção no cenário político e intelectual brasileiro e internacional. 
Em maio de 1960, na campanha para sucessão presidencial, acompanha Jânio Quadros a Cuba, para a comemoração do primeiro aniversário da Revolução. Naquele momento crescia no país o eleitorado do PTB e o peso da classe média, que via em Jânio uma saída para o combate à inflação e à corrupção, uma vez que construía sua imagem como um político austero e moralista. No ano seguinte, em 1961, com Jânio já na presidência, Milton Santos é nomeado por ele seu representante na Bahia. Conforme depoimento do próprio Milton Santos, era o representante pessoal de Jânio. Ele era a pessoa que Jânio consultava para tomar decisões, inclusive para nomear reitor (SANTOS, 2004:57):

É verdade que todos os jornalistas que foram com ele naquela
viagem foram contemplados (...). Rubem Braga foi nomeado
adido cultural e eu fui nomeado representante do presidente
na Bahia. Eu deveria ter sido nomeado embaixador em Gana,
só que no início do governo estava na França (...). Ele queria
nomear um negro (...) então nomeou outro negro, Raymundo
de Souza Dantas, pra embaixador em Gana. Quando eu
cheguei, ele me disse: "A imprensa está dando que nomeei
um embaixador negro em Gana e que isso é pouco. Você vai
ser embaixador na Suécia, mas por enquanto fique na Bahia".
Mas não deu tempo de ir para a Suécia, porque ele renunciou.
(SANTOS, 2000:84)

Nesse momento já estava cercado pelo Partido Comunista, quem produzia ideias e discursos (SANTOS, 2000 e 2004). É possível, então, afirmar que é nesse período que ocorria a ida de Milton Santos para a esquerda. Não só sua visita a Cuba, mas também sua aproximação com os comunistas brasileiros e franceses começaram a afastar Milton Santos de suas bases políticas originárias da UDN. A UDN vivia agora sua fase de anticomunismo radical.

Com a renúncia de Jânio e a posse de João Goulart, apoiado por amigos ligados a Jango, Milton Santos se afasta do mundo universitário e se dedica às atividades políticas e de planejamento. Com uma missão diplomática, viajou novamente para a África e passou a se relacionar com vários políticos vinculados aos movimentos de descolonização. Em 1962, em Penedo, Alagoas, assumiu a presidência nacional da Associação dos Geógrafos Brasileiros, com apoio de Caio Prado Junior, na época editor da Brasiliense e frequentador das reuniões da AGB, um espaço intelectual muito importante. No ano seguinte, em 1963, é nomeado chefe da Comissão de Planejamento Econômico da Bahia, no governo Antônio Lomanto Júnior, que havia sido seu colega de colégio, e naquele momento 
contava com apoio dos comunistas de João Goulart. Um grande grupo do Partido Comunista trabalhava diretamente com Milton Santos na Comissão. Segundo seu depoimento também nesse período vinha com frequência ao Rio e visitava Guerreiro Ramos e Josué de Castro, deputados na época pelo PTB (SANTOS, 2000 e 2004).

Logo após as eleições para governador, em 1963, cresceram na Bahia tensões entre posições nacionais que haviam apoiado a candidatura de Lomanto Junior, alinhadas a Jango, e as alianças locais da UDN, anticomunistas, juracistas e autonomistas. Até o golpe de 1964 aumentam as influências de Juracy Magalhães no governo da Bahia, que já naquele momento acompanhava a posição nacional udenista a favor da intervenção dos militares para afastar João Goulart. Assim, com apoio de Antonio Carlos Magalhães, na época presidindo a UDN baiana, o governo da Bahia sob o comando de Lomanto Junior apoia o golpe militar e a deposição de João Goulart, em 1964. Contra o governo Goulart unificaram-se proprietários de terras, interesses norte-americanos, a maioria das forças armadas, a UDN, parte do Partido de Ademar de Barros e outros menores, várias entidades civis e crescentes adesões de elementos militares e civis, que temiam "iminente perigo comunista".

Milton Santos, naquele momento muito envolvido no governo Goulart e presidindo a Comissão de Planejamento Econômico da Bahia, no governo Antônio Lomanto Júnior, acabou sendo preso juntamente com seus assessores comunistas. Após cem dias na prisão foi liberado e submetido à chamada prisão domiciliar, quando, com problemas cardíacos, foi auxiliado pelo banqueiro Miguel Calmon para deixar o país, aos 38 anos de idade. A turma dos alunos do geógrafo francês Pierre George, juntamente com Tricart e Jaqueline Beaujeu-Garnier articularam sua ida para a França, para lá lecionar (SANTOS, 2000 e 2004). ${ }^{23}$ Seu irmão Nailton Santos, que em 1964 era diretor da Sudene junto com o Celso Furtado, também vai para a França, ajudado por Otavio Ianni. Com o episódio do exílio, Milton Santos iniciaria uma segunda fase de sua vida e produção intelectual, simbolizada pela publicação, em 1965, do livro, também pela Civilização Brasileira, A cidade nos países subdesenvolvidos. Um Milton Santos diferente que deixava para trás a Bahia, o Brasil, sua antiga visão de mundo e, consequentemente, sua antiga visão política, e

${ }^{23}$ Milton Santos lecionou primeiro em Toulouse, Bordéus, onde conheceu Marie-Hélène, geógrafa que se tornaria sua companheira e com quem teria o filho Rafael, e Paris. Após sete anos na França, foi para os Estados Unidos, Canadá, Venezuela, Peru e Tanzânia, retornando para o Brasil em 1977. 
fazia também "a crítica do preconceito", conforme suas próprias palavras transcritas na epigrafe deste texto.

\section{A PRODUÇÃO INTELECTUAL DE MILTON SANTOS VISTA ATRAVÉS DE SUA TRAJETÓRIA ESPACIAL: UMA INTERPRETAÇÃO}

Resumo: Este artigo apresenta uma interpretação da produção intelectual do grande geógrafo brasileiro, Milton de Almeida Santos, desenvolvida a partir das observações estabelecidas entre a trajetória espacial do autor e a publicação de suas obras. Conforme será demonstrada, estreita é a associação entre o desenvolvimento intelectual do autor e seus percursos espaciais. Na parte inicial são apresentadas a hipótese deste estudo e a classificação da produção intelectual estabelecida. Em seguida, é explorada a primeira fase do pensamento de Milton Santos, vivida predominantemente na Bahia. Buscando conhecer o sentido do seu pensamento, particular atenção é dada a sua biografia e ao cenário político partidário baiano, bastante marcado naquele momento pela atuação da corrente "udenista".

Palavras-chave: Milton Santos; Geobiografia; Produção Intelectual

\section{THE INTELLECTUAL PRODUCTION OF MILTON SANTOS SEEN THROUGH ITS SPACE TRAJECTORY: AN INTERPRETATION}

Abstract: This article presents an interpretation of the intellectual output of the great Brazilian geographer, Milton Santos de Almeida, developed from observations made between the spatial trajectory of the author and the publication of his works. As will be demonstrated is the close association between the intellectual development of the author and his space journey. In the early part of this work, it is presented the hypothesis of this study and classification of intellectual production established. Then we explore the first phase of the thought of Milton Santos, lived mainly in Bahia. Seeking to know the meaning of his thought, particular attention is given to his biography and the party political scene in Bahia, well marked by the performance of the National Democratic Union, by "udenistas". 
Keywords: Milton Santos; Geobiografia; Intellectual Production.

\section{BIBLIOGRAFIA}

ANDRADE, Manuel Correia de (1997) Josué de Castro: o homem, o cientista e seu tempo. Estud. av. [online], v. 11, n. 29, pp. 169-194.

CHACON, Vamireh (1998) História dos Partidos Brasileiros. Brasília: Editora, UNB, $3^{\text {a }}$ edição ampliada e atualizada.

DICIONÁRIO HISTÓRICO-BIOGRÁFICO BRASILEIRO, CPDOC -

Fundação

Getulio

Vargas.

(http://www.cpdoc.fgv.br/comum/asp/idx_monta_login.asp), acessado em 30 de outubro de 2009.

ELIAS, Denise (2002). Milton Santos: a construção da geografia cidadã. In: El ciudadano, la globalización y la geografía. Homenaje a Milton Santos. Scripta Nova. Revista electrónica de geografía y ciencias sociales, Universidad de Barcelona, v. VI, 124, sept. (http://www.ub.es/geocrit/sn/sn-124.htm), acessado em 03 de setembro de 2009.

FRANCO, Afonso Arinos de Melo (1980). História e Teoria dos partidos políticos no Brasil. São Paulo: Editora Alfa-Omega, $3^{\text {a }}$. Edição.

GOMES, João Carlos Teixeira (2001) Memórias das trevas: uma devassa na vida de Antonio Carlos Magalhães. São Paulo: Geração Editorial.

KOIFMAN, Fábio (org.) (2002) Presidentes do Brasil. Departamento de pesquisa da Universidade Estácio de Sá. São Paulo: Cultura.

MACHADO, Mônica Sampaio (2009) A construção da Geografia universitária no Rio de Janeiro. Rio de Janeiro: Apicuri-Faperj.

PINHEIRO, Israel de Oliveira (1999). A política na Bahia: atraso e personalismo. Revista Ideação, Núcleo Interdisciplinar de Estudos e Pesquisas em Filosofia da Universidade Estadual de Feira de Santana. Bahia: Feira de Santana, n.4, p.49-78.

SANTOS, Milton (1959) O centro da cidade do Salvador: estudo de geografia urbana. Publicações da Universidade da Bahia, 196p.

(1979) Do espaço sem nação ao espaço transnacionalizado. RATTNER. Henrique (org). Brasil 1990: caminhos alternativos do desenvolvimento. São Paulo: Brasiliense, p. 143-161.

(1992) Depoimento concedido a Armen Mamigonian, Ewerton Vieira Machado, Maria Dolores Buss e Raquel Maria Fontes do Amaral 
Pereira. Revista Geosul. Santa Catarina: UFSC, n.12/13, ano VI, $1^{\circ}$ semestre p.170-201.

(1996) A natureza do espaço: técnica e tempo, razão e emoção. São Paulo: Hucitec, 308p.

(2000) Território e sociedade: entrevista com Milton Santos (entrevistadores, Odette Seabra, Mônica de Carvalho, José Corrêa Leite). São Paulo: Editora Fundação Perseu Abramo, 127 p.

(2004) Testamento intelectual/Milton Santos; entrevistado por Jesus de Paula Assis, colaboração Maria Encarnação Spósito. São Paulo: Editora Unesp.

SANTOS, Milton e SILVEIRA, Maria Laura (2001) O Brasil: território e sociedade no início do século XXI. Rio de Janeiro: Record, $471 \mathrm{p}$.

RIBEIRO, W. C. (2002). Milton Santos: aspectos de sua vida e obra. El ciudadano, la globalización y la geografía. Homenaje a Milton Santos. Scripta Nova. Revista electrónica de geografía y ciencias sociales, Universidad de Barcelona, v.VI, 124, sept. (http://www.ub.es/geocrit/sn/sn-124.htm), acessado em 16 de agosto de 2009.

SILVA, Maria Auxiliadora da. (2002). Milton Santos: a trajetória de um mestre. El ciudadano, la globalización y la geografía. Homenaje a Milton Santos. Scripta Nova. Revista electrónica de geografía y ciencias sociales, Universidad de Barcelona, v. VI, n. 124, 30 de sept. (http://www.ub.es/geocrit/sn/sn-124.htm), acessado em 22 de setembro de 2009.

Revista GEOgraphia - UFF

Data de submissão do artigo: 25/09/2011 